\title{
The effect of sea level on glacial Indo-Pacific climate
}

Pedro N. DiNezio ${ }^{1 *} \&$ Jessica E. Tierney ${ }^{2 *}$

${ }^{1}$ International Pacific Research Center, University of Hawaii, 1680 East West Road, Honolulu, HI 96822, USA

${ }^{2}$ Woods Hole Oceanographic Institution, 266 Woods Hole Road, Woods Hole, MA 02543, USA

*Both authors contributed equally to this work.

The Indo-Pacific Warm Pool - the Earth's largest body of warm water and main source of

heat and moisture to the global atmosphere - plays a prominent role in tropical and global climate change. The physical mechanisms driving changes in the warm pool over glacialinterglacial timescales are largely unknown. Here we show that during the Last Glacial Maximum (LGM) changes in global sea level influenced tropical climate by exposing the Sunda Shelf and altering the Walker Circulation. Our result is based on a synthesis of marine and terrestrial proxies sensitive to hydroclimate and a multi-model ensemble of climate simulations. The proxy data suggest drying throughout the warm pool, and wetter conditions in the western Indian and Pacific oceans. Only one model out of twelve simulates a similar pattern of hydroclimate change, as measured by the Cohen's $\kappa$ statistic. According to this model, weakened convection over the warm pool in response to exposure of the Sunda Shelf drives the proxy-inferred hydrological changes. Our study demonstrates that on glacial-interglacial timescales, ice sheets exert a first order influence on tropical climate through changes in global sea level. 


\section{Theories of tropical climate change}

The Indo-Pacific Warm Pool (IPWP) - the vast body of warm water stretching along the equator from the Indian ocean, through the waters off Sumatra, Java, Borneo, and New Guinea, to the western Pacific Ocean - is the most prominent feature of the Earth's tropics. In the present-day climate, the IPWP consists of sea-surface temperatures (SST) exceeding $28^{\circ} \mathrm{C}$ which favor strong convective activity and heavy rainfall (Fig. 1a) resulting in relatively fresh sea-surface salinity

(Fig. 1b). The rising motion associated with IPWP convection is closed by subsiding motion over the central and eastern Pacific, constituting the Walker circulation ${ }^{1}$. Variations in IPWP convection and the Walker circulation - such as those associated with the El Niño/Southern Oscillation (ENSO) and the Asian and Australian monsoons - have far-reaching climate impacts ${ }^{2,3}$. Given suggestions that IPWP climate could fundamentally change in response to external forcings ${ }^{4-8}$, understanding the physical mechanisms driving IPWP variability and the corresponding changes in deep tropical convection is of paramount importance.

Studies of both past and future climates invoke several possible mechanisms to explain how the IPWP and the Walker circulation respond to global warming or cooling. One mechanism posits that the tight coupling between year-to-year changes in the Walker circulation and the Pacific equatorial SST gradient (the Bjerknes feedback) also operates on longer timescales. The Pacific SST gradient could strengthen in response to global warming, as increased ocean stratification enhances the upwelling-driven cooling over the cold tongue, and result in a stronger Walker circulation and wetter IPWP ${ }^{9}$. Conversely, this “ocean dynamical thermostat" predicts a weaker 
SST gradient - with weaker Walker circulation and a drier IPWP - in response to global cooling. However, recent studies suggest that the response of the tropics may be dominated by other mechanisms than the SST gradient ${ }^{10,11}$. One theory posits that because rainfall and moisture increase at different rates in response to warming, the Walker circulation has to weaken in order to maintain a balanced flow of water vapor into areas of convection over the IPWP ${ }^{4,5}$. Conversely, this "weaker Walker" mechanism predicts that the Walker circulation should strengthen in response to global cooling (i.e., "stronger Walker") ${ }^{11}$ - the opposite of the predicted response from the thermostat mechanism. In addition, large changes in tropical hydroclimate can occur even in the absence of circulation changes. Rainfall is expected to increase over regions that already have strong moisture convergence and a positive precipitation-evaporation $(P-E)$ balance, such as the IPWP, as the moisture content of the atmosphere increases in a warmer climate, the so-called “wet-get-wetter" mechanism ${ }^{12,13}$. Conversely, this mechanism would lead to decreased rainfall over the IPWP during periods of global cooling due to reduced atmospheric moisture ${ }^{14}$.

These mechanisms are common features of both paleoclimate ${ }^{11,14}$ and future climate ${ }^{5,7}$ model simulations, but they remain largely untested because the historical record lacks the coverage and length to detect forced changes against the background of natural variability ${ }^{15-17}$. The Last Glacial Maximum (LGM) - the period during the last ice age when ice sheets were at their maximum extent - serves as a laboratory in which to explore these mechanisms. The LGM is one of the most important paleoclimate reference periods used to evaluate numerical models' ability to simulate climates radically different from the present one, as a large amount of proxy data are available to compare with model simulations ${ }^{18-20}$. Via proxy-model comparison, the LGM has 
been used to study fundamental aspects of the Earth's climate such as climate feedbacks ${ }^{21,22}$ and climate sensitivity ${ }^{23}$. Regarding tropical climate, previous studies have largely focused on testing for the presence of a weaker SST gradient during the LGM as an indication of the "ocean dynamical thermostat" ${ }^{24-28}$. However, tropical SST proxies are not conclusive, variously suggesting that the SST gradient was weaker ${ }^{24,25}$, stronger ${ }^{26,27}$ or minimally changed ${ }^{28}$ relative to the present day. This ambiguity in the proxy SST data may reflect the small signal-to-noise ratio between the expected tropical SST change $\left(2-3^{\circ} \mathrm{C}\right)$ and the typical proxy error $\left(1-3^{\circ} \mathrm{C}\right)$, or alternatively, simply suggests that a different mechanism influenced tropical climate during the LGM.

\section{Proxy-model synthesis}

To better understand the tropical response to glacial background conditions, we created a synthesis of IPWP hydroclimate during the LGM using proxy data and climate model simulations. Given the inconclusive proxy SST data and the indication from model simulations that changes in atmospheric circulation should have a larger and more direct signature on rainfall than on SST gradients ${ }^{11}$, we focused our study on identifying changes in proxies that are directly sensitive to hydroclimate. We considered both precipitation and sea-surface salinity (SSS) proxies derived from terrestrial and marine records, as they capture hydrological responses over land and ocean respectively. The terrestrial data include a wide variety of proxies capable of inferring relative changes in water balance, such as $\delta^{18} \mathrm{O}$ of speleothems, charcoal, relative abundances of diatoms or pollen, lake levels, and evidence for increased dune activity or desiccated lakes. The salinity proxies primarily consist of inferred $\delta^{18} \mathrm{O}$ of sea water (from paired $\delta^{18} \mathrm{O}-\mathrm{Mg} / \mathrm{Ca}$ measure- 
ments on planktonic foraminifera) or SSS reconstructions using foraminifera transfer functions.

In many cases, quantitative transfer functions to absolute values of precipitation and salinity from proxy data are not possible or carry significant uncertainties. Thus, for each proxy record, we simply classified the LGM response (defined as data falling within 26.5-19 $\mathrm{ka}$ in line with the duration of the LGM sea-level lowstand $\left.{ }^{21}\right)$ relative to late Holocene (0-4 ka) conditions as either drier, unchanged, or wetter (for precipitation) or saltier, unchanged, or fresher (for salinity). We classified the salinity data with the expected change in mean ocean salinity (1 psu) and $\delta^{18} \mathrm{O}$ composition $(1 \%)$ due to the presence of ice sheets removed in order to isolate the hydroclimatic signature. Our synthesis resulted in a network of 53 terrestrial locations (47 with robust data) representing 61 precipitation proxy records and 54 marine locations (47 with robust data) representing 66 SSS proxy records (Fig. 2a and 3a, and see Methods and Supplementary Information).

To identify mechanisms driving the proxy-inferred patterns of change, we employed an ensemble of twelve LGM climate simulations conducted as part of the Paleoclimate Modeling Intercomparison Project (PMIP) ${ }^{18}$ (see Methods). We also computed the expected pattern of rainfall and SSS change arising from the thermodynamic reduction in moisture convergence and associated $P-E$ balance, which is governed by the Clausius-Clapeyron (C-C) equation. We included this "wet-get-drier" pattern in our proxy-model comparison as a null hypothesis due to the simplicity of its physics (see Supplementary Information). According to this mechanism, wet regions, such as the IPWP, become drier; and dry regions, such as northern Australia, become wetter in response to global cooling. For the models that specified a change in global mean salinity due to the presence of ice sheets ( $\sim 1 \mathrm{psu})$ we removed said change to facilitate comparison with the 
proxies (see Methods).

\section{Warm pool hydroclimate during the LGM}

The changes in rainfall inferred from the proxies suggest an overall drying of the tropical Indo-

Pacific at the LGM, but with some notable departures, including regionally wetter conditions in easternmost Africa and no change in hydroclimate in west Sumatra and Papua New Guinea (Fig.

2a). Despite the common forcing (changes in orbital configuration, greenhouse gases, ice sheets, and coastlines), the models simulate a wide range of hydroclimate responses (Fig. 2b), due in part to different simulated changes in the Walker circulation ${ }^{11}$. The ensemble of models simulates a tropical mean $\left(25^{\circ} \mathrm{S}-25^{\circ} \mathrm{N}\right)$ cooling of -4.2 to $-1.6 \mathrm{~K}$, thus the expected thermodynamic drying - which is governed by the $7 \%$ moisture change per degree of cooling from the $\mathrm{C}-\mathrm{C}$ equation - should range from 11 to $30 \%$. Many models, however, simulate a muted rainfall response over the Maritime continent (southeast Asia, Indonesia, New Guinea, and the Philippines) because a strengthening in the ascending branch of the Walker circulation partially counteracts the thermodynamic drying (Fig. 2b) ${ }^{11}$. A few models (HadCM3, GFDL 2.1, IPSL-CM4, MPI-ESMP, MRI-CGCM3) simulate widespread drying over the Maritime continent in excess of the 11$30 \%$ range expected from the thermodynamic effect.

Over the ocean, the proxies exhibit large-scale patterns of SSS change with saltier conditions in the Bay of Bengal, and fresher conditions in the Arabian Sea, the South China Sea and the western Pacific (Fig. 3a). In general, the simulated patterns of SSS change (Fig. 3b) reflect the 
lack of agreement evident in the rainfall changes (Fig. 2b). This is especially the case in the Indian Ocean, where some models (FGOALSg1.0, CCSM3.0) simulate a saltier Arabian Sea in line with less precipitation, and other models (GFDL-CM2.1, IPSL-CM4, HadCM3) simulate fresher conditions in line with more precipitation over the western Indian ocean (Fig. 2b). The SSS and precipitation patterns are not perfectly aligned due to the influence of ocean advection: e.g., in HadCM3, the Somali current advects the freshwater anomaly in the western Indian Ocean throughout the Arabian Sea, and in the eastern side of the basin, the South Equatorial Current carries the saltier conditions that result from a reduction in precipitation further towards the southwest. The changes in SSS due to changes in $P-E$ associated with the thermodynamic effect ("wet-get-drier") correspond to a simple reduction in the spatial contrast of present-day SSS (Fig. $3 b$ top left panel).

The models suggest a large range of possible IPWP hydroclimatic responses to LGM forcing. The proxy data, however, provide a target pattern that, when compared to the simulations, should yield information regarding which mechanisms affected actual hydroclimate during the LGM. In order to identify these mechanisms, we estimate the pattern agreement between models and proxies using the weighted Cohen's kappa $(\kappa)$ statistic, a metric used to assess "inter-rater" agreement given categorical data ${ }^{29,30}$ (see Methods). In our case the raters are the models and the proxies. Cohen's $\kappa$ ranges from $\kappa=1$ if a model is in complete agreement with the proxies, to $\kappa=0$ if the agreement could be expected entirely by chance. We explore the sensitivity of the $\kappa$ values by varying the thresholds of rainfall and salinity change over which we place the model output into the same categories of change assigned to the proxies (Figs. 2c and 3c). Amongst the twelve sim- 
ulations, HadCM3 is the sole model exhibiting statistically significant $(p<0.05)$ agreement with the proxies for changes in rainfall up to ca. 20\% (Fig. 2c). The superior performance of HadCM3 over the other models, as well as the wet-get-drier null hypothesis, reflects the fact that this model correctly simulates the pattern of a wet easternmost Africa along with strong and widespread drying over the Maritime continent extending into southeast Asia and northern Australia. Drying in northern Australia is particularly notable, as the thermodynamic effect would predict an increase in rainfall there.

HadCM3 also outperforms the other PMIP models in terms of a proxy data match for SSS, with statistically significant Cohen's $\kappa$ values of up to 0.27 for a SSS change threshold from 0.1 to 0.3 psu (Fig. 3c). In this case, the match between the proxy data and HadCM3 reflects the ability of this model to correctly simulate fresh conditions in the Arabian Sea, salty conditions in the eastern Indian Ocean and Bay of Bengal, and fresh conditions in the western Pacific. As with the precipitation proxies, the SSS changes simulated by HadCM3 are in better agreement with the proxies than the wet-get-drier pattern (Fig. 3b, top left). In the latter, some freshening occurs locally in the Arabian Sea, but it is not as widespread as in HadCM3 because there is no increase in rainfall over the equatorial western Indian Ocean. A fresher western Pacific - an important feature of the proxy SSS data - cannot result from the thermodynamic effect, and thus circulation changes must be invoked to explain it. 


\section{Effect of Sunda shelf exposure on Walker circulation}

The marine records and the terrestrial records represent completely independent archives of LGM hydroclimate, yet both sets of data agree best with the HadCM3 simulation. This result seems insensitive to uncertainties surrounding the dating of proxies and their seasonal expression (see Supplementary Information), and points to a common mechanism driving IPWP hydroclimate response during the LGM. Examining HadCM3's changes in tropical circulation, we find that the ascending branch of the Walker circulation is involved in this response. HadCM3 simulates a large reduction in convection over the Maritime continent in response to LGM forcing, as shown by the subsidence anomaly $(\Delta \omega>0)$ on the equator between $100^{\circ} \mathrm{E}$ and $110^{\circ} \mathrm{E}$ (Fig. $\left.4 \mathrm{a}\right)$. This is the region set to land in the LGM simulations to represent the exposure of the Sunda Shelf due to lowered sea level. The exposed land cools more than the surrounding ocean, inducing air flow divergence and anomalous subsidence (Fig. S3). The result is widespread drying over the Maritime Continent and saltier SSS extending off the coast of Java. The change in vertical motion over the Sunda Shelf is compensated by increased ascending motion and convection $(\Delta \omega<0)$ over the western Indian Ocean, resulting in increased rainfall extending to the East African coast and a freshening of the Arabian Sea.

HadCM3 outperforms the other models because it is the sole model simulating the pattern of reduced convection $\left(\Delta \omega_{500}>0\right)$ over the Maritime Continent and increased convection $\left(\Delta \omega_{500}<\right.$ 0) over the western Indian ocean, i.e. a weaker Walker circulation over the Indian ocean (Fig. 4b, red line). Some of the models (GFDL-CM2.1, IPSL-CM4, and MPI-ESM-P) simulate a similar 
pattern, but with weaker magnitude, especially over the western Indian ocean (Fig. 4b), explaining why these models do not fully capture the pattern of a wetter east Africa and fresher Arabian sea suggested by the proxies. The remaining seven models simulate a diversity of patterns, including enhanced convection over the Sunda Shelf (Fig. 4b, gray lines).

Over the Pacific, HadCM3 simulates off-equatorial increases in convection (Fig. S5) and associated freshening (Fig. 3b), along with increased subsidence in the subsiding branch of the Walker cell towards the East (Fig. 4a). Two patterns shown by our proxy synthesis - the lack of drying over northeastern Papua New Guinea (Fig. 2a), and the fresher SSS in the western equatorial Pacific (Fig. 3a) - are consistent with this regional strengthening of tropical circulation in the northwestern tropical Pacific. This response may be a manifestation of a stronger Pacific Walker circulation, which could be a response to either a stronger SST gradient or changes in the hydrological cycle ${ }^{11}$.

Our analysis suggests that changes in the atmospheric circulation over the Indian Ocean driven by the exposure of the Sunda Shelf best explain the pattern of hydroclimatic change inferred from the proxies. This finding agrees with past studies invoking the Sunda Shelf as a cause of widespread drying across Indonesia and northern Australia ${ }^{31}$, and further suggests that Shelf exposure affects the western Indian Ocean region via a weakening of Indian Ocean Walker Circulation. This response appears to be decoupled from that of the Walker circulation over the Pacific, which strengthens in HadCM3 in order to keep a balanced flow of water vapor over areas of convection in the western Pacific. This may partially explain the fresher conditions in the western 
Pacific. In sum, the "Sunda Shelf mechanism" overwhelms the thermodynamic ("wet-get-drier") response and to some extent the influence of a stronger Pacific Walker circulation. There is no evidence - either in our simulations or the proxy data - implicating the "ocean dynamical thermostat". Furthermore, the circulation changes simulated by HadCM3 show that convection over the IPWP weakens, yet the area where convection occurs expands - both westward, due to the weaker Walker circulation over the Indian ocean, and eastward, due to the stronger Walker circulation over the Pacific (i.e., the dynamical definition of IPWP extension ${ }^{32}$ ). Thus, analogies with present-day El Niño or La Niña fail to describe tropical climate change during the LGM.

The importance of continental shelf exposure on IPWP hydrology suggests that sea level, and therefore ice sheet extent, is a first-order driver of tropical hydroclimate on glacial-interglacial timescales. Transient paleoclimate studies from core regions of the diagnostic pattern seen during the LGM will serve as critical tests for this hypothesis. Recent stalagmite data from southern Indonesia are supportive, suggesting that lowered sea level had a large effect on IPWP hydroclimate from the LGM to $9.5 \mathrm{ka}$, when the Shelf was nearly flooded ${ }^{33,34}$. The Sunda Shelf mechanism is not directly translatable to the global warming scenario - i.e., we do not expect that future sea level changes will drive tropical circulation changes - but it highlights the sensitivity of the tropical climate system to zonal asymmetries, reminding us that future climate change is unlikely to be solely dictated by the zonally symmetric "wet-get-wetter" mechanism and that changes in circulation are important ${ }^{14,35}$. Critically, the fact that only one out of the twelve models simulates a response in LGM hydroclimate in agreement with the proxies presents a clear challenge for model simulations of tropical climates both past and future, and also reflects the fact that 
both proxies and models are highly uncertain renditions of climate history. A multi-proxy, multimodel approach is arguably the most effective way to both understand past climates and improve future climate change projections.

\section{Methods}

Multi-proxy synthesis. We compiled a synthesis of LGM hydroclimate change using both published, publicly archived data and data available via personal communication with authors, employing the following criteria: 1) the proxy used is interpreted to reflect hydroclimate, 2) the proxy record includes data during both the Last Glacial Maximum (26.5-19 ka) and the Late Holocene (0-4 ka) for comparison and 3) the proxy site is located within $25^{\circ} \mathrm{S}-20^{\circ} \mathrm{N}, 25^{\circ}-170^{\circ} \mathrm{E}$. The reader is referred to the Supplementary Information for further discussion of proxy selection criteria, detailed discussions of the proxy data from key regions, the potential effect of Heinrich events on the multi-proxy synthesis, and the merging of nearby proxies to avoid over-representing well-sampled regions. A complete list of proxies used may be found in Tables S1 and S2.

Climate Model Experiments. We compare the multi-proxy synthesis with simulated changes in LGM climate from an ensemble of climate model experiments coordinated by the Paleoclimate Modeling Intercomparison Project (PMIP) Phase II and Phase III ${ }^{18}$ (see Supplementary Information for further details). The changes in hydroclimate simulated by each model are computed as the difference in annual-mean conditions between the LGM and the preindustrial (PI) climates. The forcings and boundary conditions used in the LGM simulations consist of: 1) reduced greenhouse gas (GHG) concentrations (185 ppm for $\mathrm{CO}_{2}, 350 \mathrm{ppb}$ for $\mathrm{CH}_{4}$, and $200 \mathrm{ppb}$ for $\mathrm{N}_{2} \mathrm{O}$ ), 2) 
insolation changes due to the orbital configuration 21,000 yr before present, 3) surface albedo changes due to prescribed ice sheets and corresponding roughness length, 4) orography changes due to prescribed ice sheets, and 5) changes in the land-sea distribution and altitude due to lowered sea level during the LGM $(\sim 120 \mathrm{~m})$. The experiments prescribe ice sheet topography and snow cover extent and do not include interactive ice sheet models. The LGM experiments performed for PMIP2 do not include interactive vegetation models or the carbon cycle; vegetation is prescribed to be the same as in the control simulation except for the regions covered by ice sheets or exposed due to lowered sea level. Two of the LGM simulations performed for PMIP3 were performed with Earth System Models (ESM), which simulate changes in vegetation and the carbon cycle, but $\mathrm{CO}_{2}, \mathrm{CH}_{4}$, and $\mathrm{N}_{2} \mathrm{O}$ concentrations are still prescribed. Dust and other aerosols (volcanism) are not considered. The PI simulations were forced with insolation corresponding to year 1950, and GHG concentrations correspond to pre-industrial values of $280 \mathrm{ppm}$ for $\mathrm{CO}_{2}, 760$ ppb for $\mathrm{CH}_{4}$, and $270 \mathrm{ppb}$ for $\mathrm{N}_{2} \mathrm{O}$. Information on the models' resolutions can be found in Table S3.

PMIP2 and PMIP3 handled the changes in global mean salinity due to the reduction in sea level differently. For PMIP3, a uniform 1 psu adjustment was applied to the LGM simulations as an initial boundary condition. For PMIP2, only CCSM3.0 and GFDL CM2.1 prescribed a 1 psu change. To compare these simulations consistently with the proxies (which have mean ocean salinity changes removed) we removed 1 psu from those LGM simulations that had it applied, i.e. CCSM3.0, GFDL-CM2.1, and all PMIP3 models. 
Proxy-Model comparison. In order to compare models with proxies, we place the simulated changes in precipitation and SSS into the same categories as the proxies (drier, unchanged, or wetter; saltier, unchanged, or fresher), varying the threshold used in this categorization to explore the robustness of the model-proxy agreement (see Supplementary Information for details). We then quantify each model's agreement with the proxies using the Cohen's $\kappa$ statistic $^{29}$, defined as the observed fractional agreement $\left(p_{o}\right)$ relative to the probability of random agreement $\left(p_{e}\right)$ :

$$
\kappa=\frac{p_{o}-p_{e}}{1-p_{e}}
$$

where $p_{o}$ is the fractional agreement among the raters, i.e. the sum of the diagonal elements in the comparison matrix (see Supplementary Information for an example) divided by the number of items, $N \cdot p_{e}$ is the probability that the raters agree due to random chance and is computed from the observed data as the frequency of occurrence of each category, i.e. the product of the sum of the respective rows normalized by $N$. If the raters are in complete agreement then $\kappa=1$. If there is no agreement among the raters other than what would be expected by chance, i.e. $p_{o}=p_{e}, \kappa$ $=0$. In our case, we use a slightly modified version of Cohen's $\kappa$, the weighted Cohen's $\kappa^{30}$, in which multiplying the data by a weight matrix penalizes models for a total miss (e.g., drier when it should be wetter) more than a near miss (e.g., drier when it should be no change). Specifically, we assign a near miss 0.5 of the weight given to total agreement (e.g. drier-drier agreement).

Data. The proxy data synthesis is available for download from NOAA's National Climatic Data Centre's Paleoclimatology database (http://www.ncdc.noaa.gov/paleo/paleo.html) and at the following URL: http://iprc.soest.hawaii.edu/users/pdn/papers/DNT13/LGM_hydroclimate_proxy_data.mat. The 
model data is available at the PMIP2 (http://pmip2.lsce.ipsl.fr/pmip2/) and CMIP5/PMIP3 (http://cmip-pcmdi.llnl.gov/cmip5/) web sites.

\section{References}

1. Bjerknes, J. Atmospheric teleconnections from the equatorial pacific. Monthly Weather Review 97, 163-172 (1969).

2. Deser, C. \& Wallace, J. M. Large-Scale Atmospheric Circulation Features of Warm and Cold Episodes in the Tropical Pacific. Journal of Climate 3, 1254-1281 (1990).

3. Webster, P. J. et al. Monsoons: Processes, predictability, and the prospects for prediction. Journal of Geophysical Research: Oceans 103, 14451-14510 (1998).

4. Vecchi, G. A. et al. Weakening of tropical Pacific atmospheric circulation due to anthropogenic forcing. Nature 441, 73-76 (2006).

5. Vecchi, G. A. \& Soden, B. J. Global Warming and the Weakening of the Tropical Circulation. Journal of Climate 20, 4316-4340 (2007).

6. Meehl, G. A. et al. Global climate projections. In Solomon, S. et al. (eds.) Climate Change 2007: The Physical Science Basis. Contribution of Working Group I to the Fourth Assessment Report of the Intergovernmental Panel on Climate Change (Cambridge University Press, Cambridge, United Kingdom and New York, NY, USA, 2007). 
7. DiNezio, P. N. et al. Climate Response of the Equatorial Pacific to Global Warming. Journal of Climate 22, 4873-4892 (2009).

8. Xie, S.-P. et al. Global Warming Pattern Formation: Sea Surface Temperature and Rainfall. Journal of Climate 23, 966-986 (2010).

9. Clement, A., Seager, R., Cane, M. \& Zebiak, S. An ocean dynamical thermostat. Journal of Climate 9, 2190-2196 (1996).

10. DiNezio, P., Clement, A. \& Vecchi, G. Reconciling Differing Views of Tropical Pacific Climate Change. Eos Trans. AGU 91 (2010).

11. DiNezio, P. et al. The response of the Walker circulation to Last Glacial Maximum forcing: Implications for detection in proxies. Paleoceanography 26, PA3217 (2011).

12. Chou, C. \& Neelin, J. D. Mechanisms of Global Warming Impacts on Regional Tropical Precipitation. Journal of Climate 17, 2688-2701 (2004).

13. Held, I. M. \& Soden, B. J. Robust Responses of the Hydrological Cycle to Global Warming. Journal of Climate 19, 5686-5699 (2006).

14. Boos, W. R. Thermodynamic Scaling of the Hydrological Cycle of the Last Glacial Maximum. Journal of Climate 25, 992-1006 (2012).

15. Zhang, X. et al. Detection of human influence on twentieth-century precipitation trends. Nature 448, 461-465 (2007). 
16. Wentz, F. J. et al. How much more rain will global warming bring? Science 317, 233-235 (2007).

17. Tokinaga, H., Xie, S., Deser, C., Kosaka, Y. \& Okumura, Y. Slowdown of the Walker circulation driven by tropical Indo-Pacific warming. Nature 491, 439-443 (2012).

18. Braconnot, P. et al. Results of PMIP2 coupled simulations of the Mid-Holocene and Last Glacial Maximum, Part 1: experiments and large-scale features. Climate of the Past 3, 261277 (2007).

19. Otto-Bliesner, B. et al. A comparison of PMIP2 model simulations and the MARGO proxy reconstruction for tropical sea surface temperatures at Last Glacial Maximum. Climate Dynamics 32, 799-815 (2009).

20. Braconnot, P. et al. Evaluation of climate models using palaeoclimatic data. Nature Clim. Change 2, 417-424 (2012).

21. Clark, P. et al. The Last Glacial Maximum. Science 325, 710-714 (2009).

22. Shakun, J. et al. Global warming preceded by increasing carbon dioxide concentrations during the last deglaciation. Nature 484, 49-54 (2012).

23. Schmittner, A. et al. Climate Sensitivity Estimated from Temperature Reconstructions of the Last Glacial Maximum. Science 334, 1385-1388 (2011).

24. Koutavas, A., Lynch-Stieglitz, J., Marchitto, T. M. \& Sachs, J. P. El Niño-Like Pattern in Ice Age Tropical Pacific Sea Surface Temperature. Science 297, 226-230 (2002). 
25. Koutavas, A. \& Joanides, S. El Niño-Southern Oscillation extrema in the Holocene and Last Glacial Maximum. Paleoceanography 27, PA4208 (2012).

26. Andreasen, D. J. \& Ravelo, A. C. Tropical Pacific Ocean Thermocline Depth Reconstructions for the Last Glacial Maximum. Paleoceanography 12, 395-413 (1997).

27. Lea, D. W., Pak, D. K. \& Spero, H. J. Climate Impact of Late Quaternary Equatorial Pacific Sea Surface Temperature Variations. Science 289, 1719-1724 (2000).

28. Waelbroeck, C. et al. Constraints on the magnitude and patterns of ocean cooling at the Last Glacial Maximum. Nature Geoscience 2, 127-132 (2009).

29. Cohen, J. A coefficient of agreement for nominal scales. Educational and psychological measurement 20, 37-46 (1960).

30. Cohen, J. Weighted kappa: nominal scale agreement with provision for scaled disagreement or partial credit. Psychological Bulletin 70, 213-220 (1968).

31. De Deckker, P., Tapper, N. \& van der Kaars, S. The status of the Indo-Pacific Warm Pool and adjacent land at the Last Glacial Maximum. Global and Planetary Change 35, 25-35 (2002).

32. Hoyos, C. \& Webster, P. Evolution and modulation of tropical heating from the last glacial maximum through the twenty-first century. Climate Dynamics 38, 1501-1519 (2012).

33. Griffiths, M. L. et al. Increasing Australian-Indonesian monsoon rainfall linked to early Holocene sea-level rise. Nature Geosci. 2, 636-639 (2009). 
34. Griffiths, M. et al. Abrupt increase in east Indonesian rainfall from flooding of the Sunda Shelf $~ 9500$ years ago. Quaternary Science Reviews in press (2012).

35. Chou, C., Neelin, J. D., Chen, C.-A. \& Tu, J.-Y. Evaluating the "Rich-Get-Richer" Mechanism in Tropical Precipitation Change under Global Warming. Journal of Climate 22, 19822005 (2009).

36. Adler, R. F. et al. The Version-2 Global Precipitation Climatology Project (GPCP) Monthly Precipitation Analysis (1979-Present). Journal of Hydrometeorology 4, 1147-1167 (2003).

37. Antonov, J. I. et al. World Ocean Atlas 2009, Volume 2: Salinity, 184 (U.S. Government Printing Office, 2010).

38. Reynolds, R. W., Rayner, N. A., Smith, T. M., Stokes, D. C. \& Wang, W. An Improved In Situ and Satellite SST Analysis for Climate. Journal of Climate 15, 1609-1625 (2002).

Acknowledgements We thank A. Clement, A. Timmermann, and three anonymous reviewers for their comments. We gratefully acknowledge the climate modeling groups participating in PMIP2 and CMIP5/PMIP3 for producing and making their model output available, and the PMIP2/MOTIF Data Archive (supported by CEA, CNRS, the EU project MOTIF and PNEDC) and PCMDI (supported by the U.S. Department of Energy) for distributing the data. Funding for this work was provided by NSF (grant AGS 1204011) and the University of Hawaii.

Author Contributions PDN and JET contributed equally to the synthesis of the proxy and model data and the writing of this manuscript. 
Competing Interests The authors declare that they have no competing financial interests.

Correspondence Correspondence and requests for materials should be addressed to PDN. (email: pdn@ hawaii.edu). 
(a)

Present-day rainfall

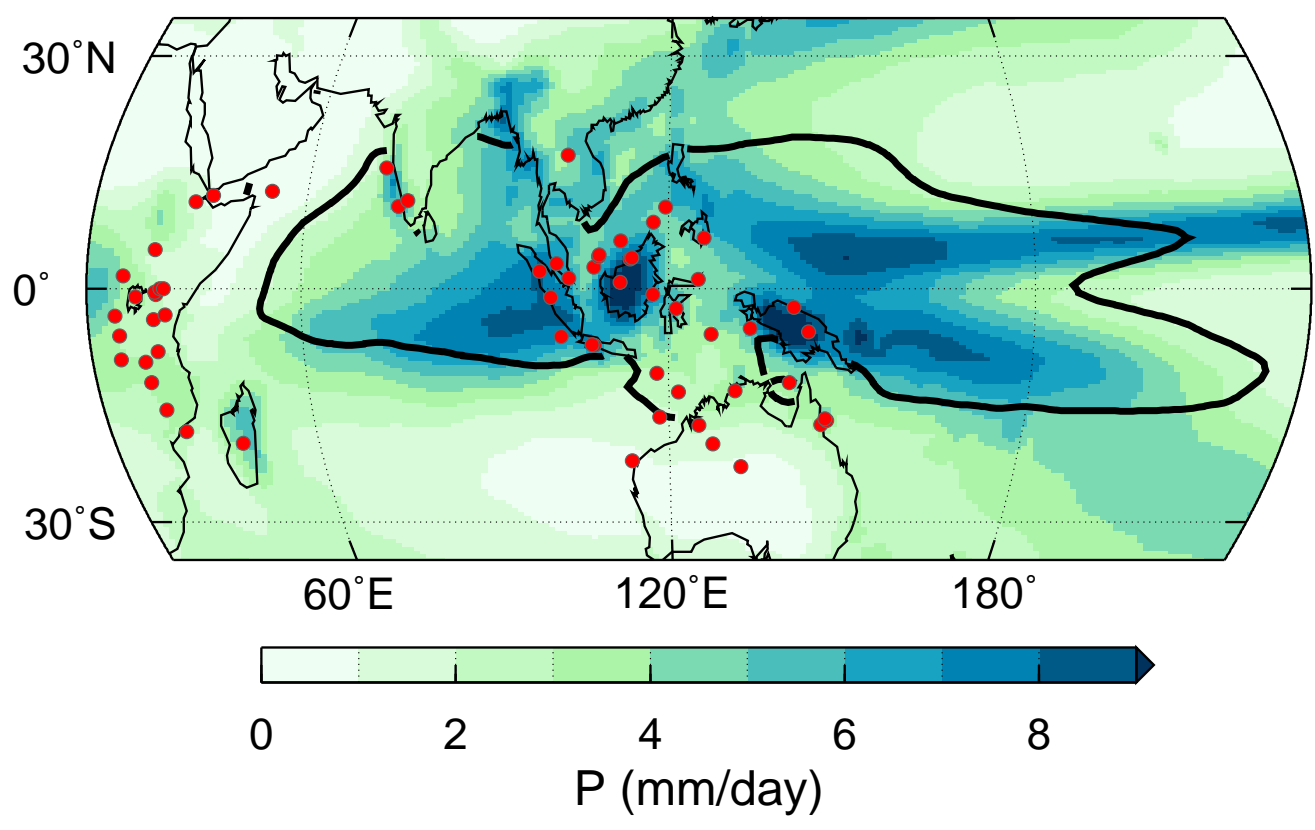

(b) Present-day sea-surface salinity

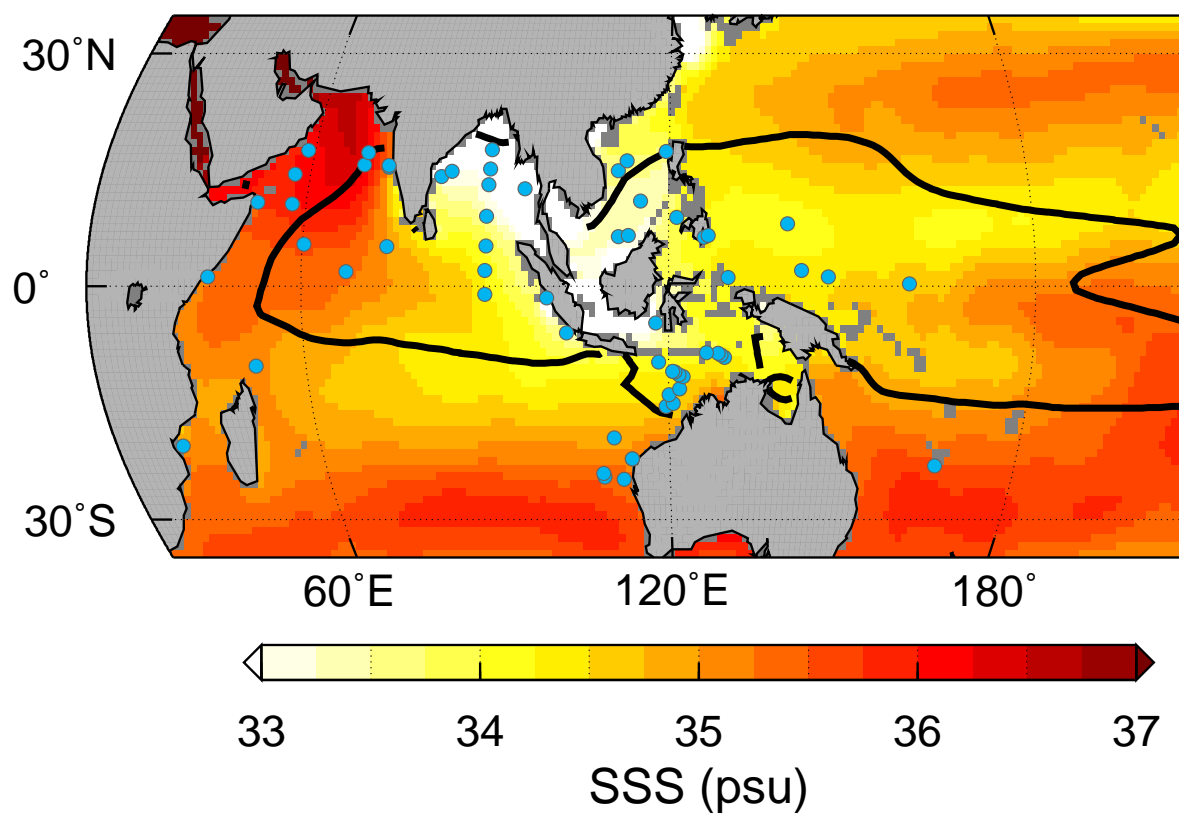


(a)

Proxy network

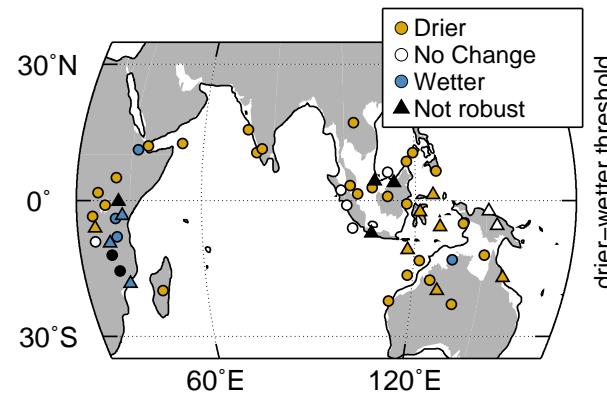

(b) Simulated rainfall change (c) Proxy-model agreement

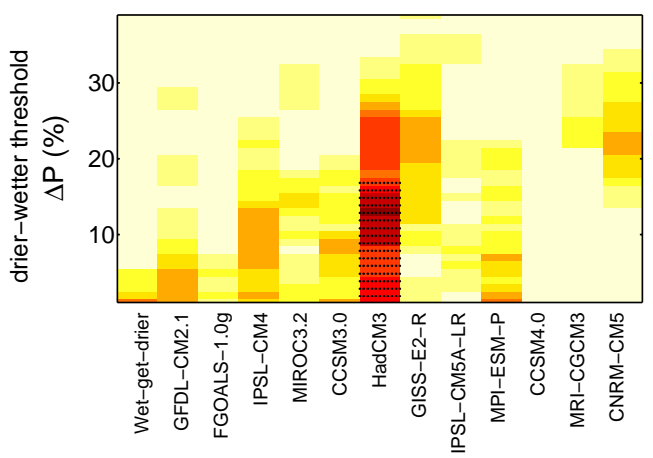

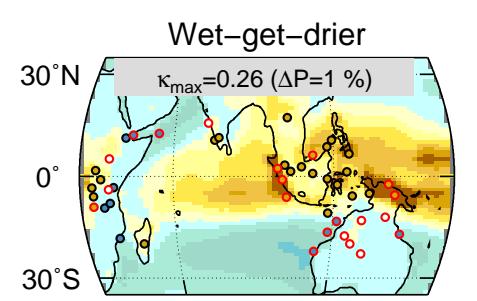
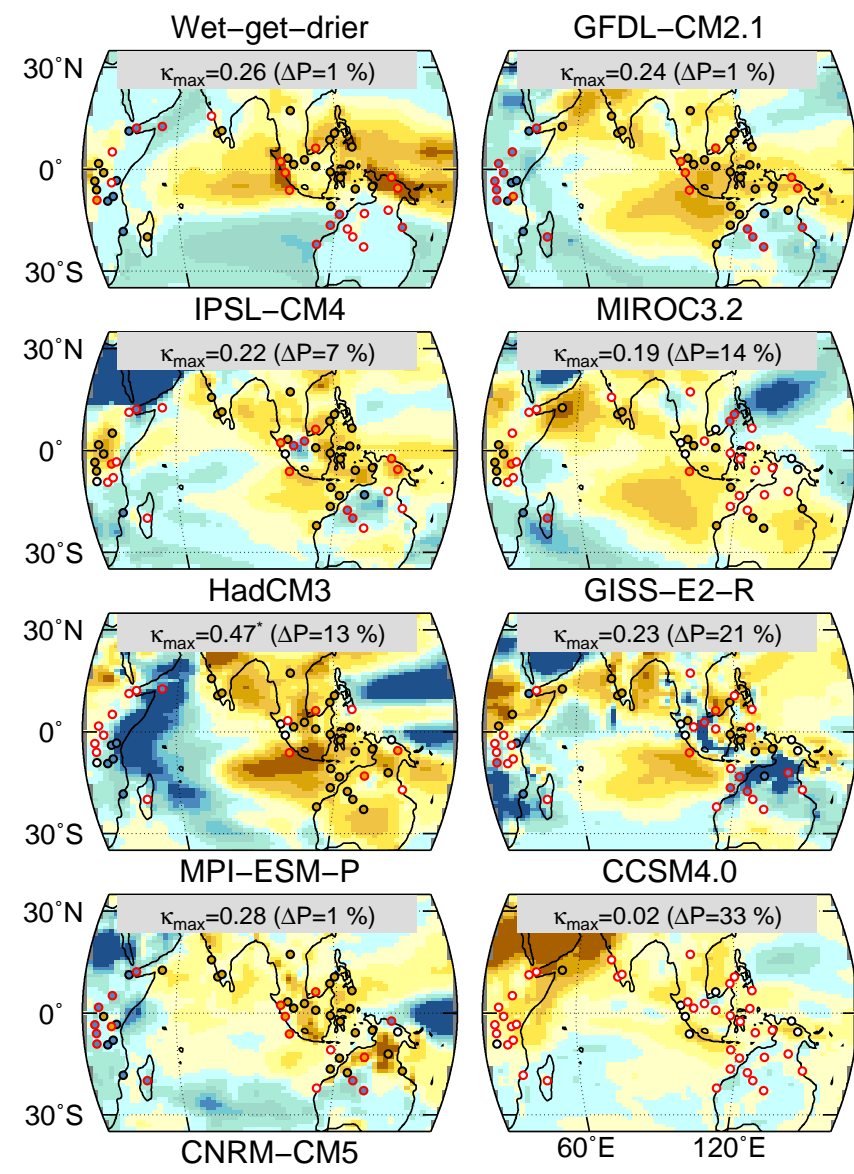

MIROC3.2

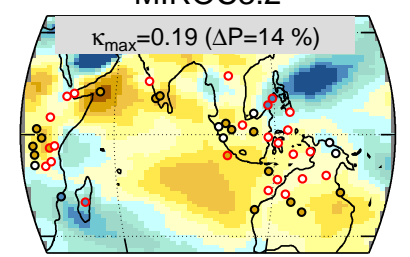

GISS-E2-R

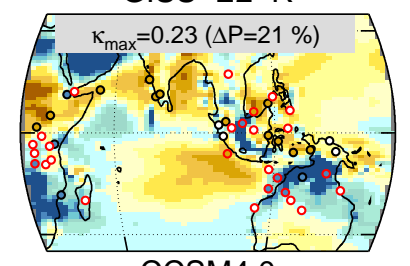

$\begin{array}{cccc}0.2 & 0.3 & 0.4 & 0.5 \\ \text { Cohen's } \kappa & & \end{array}$
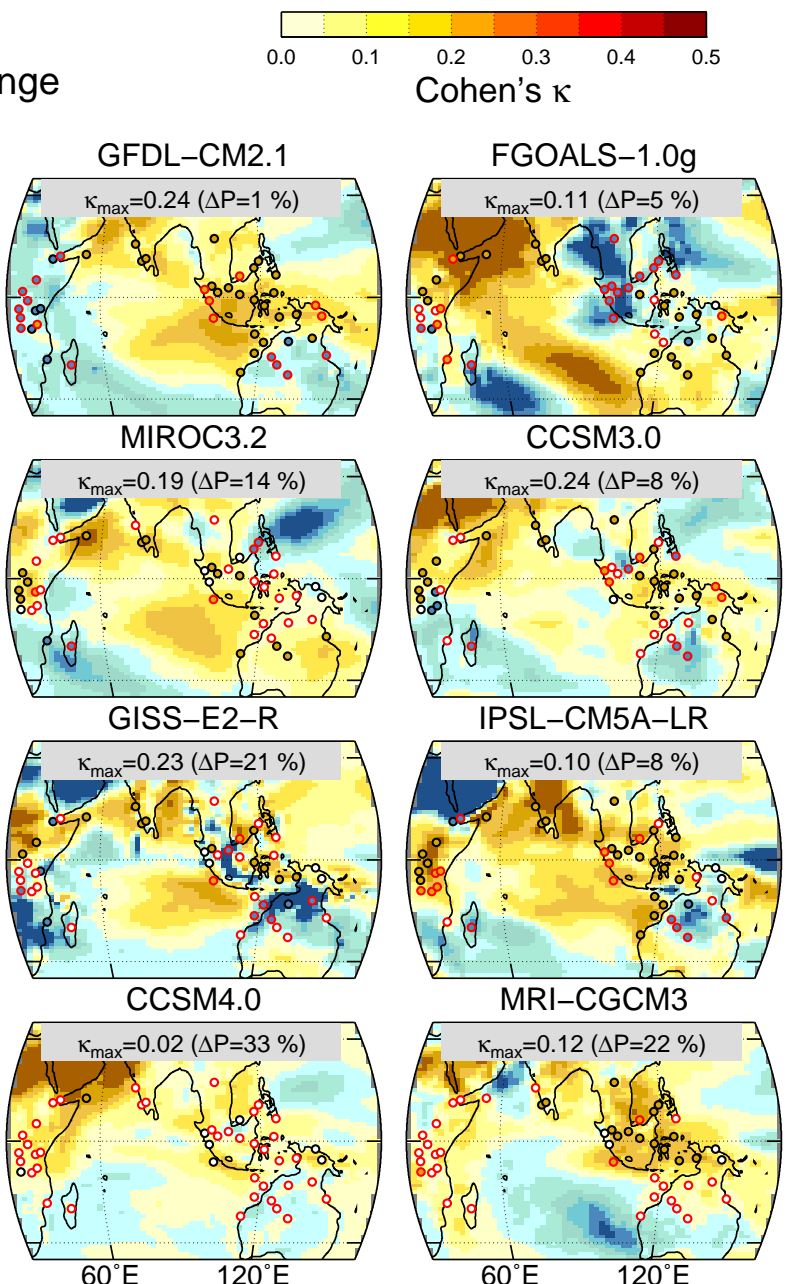

IPSL-CM5A-LR

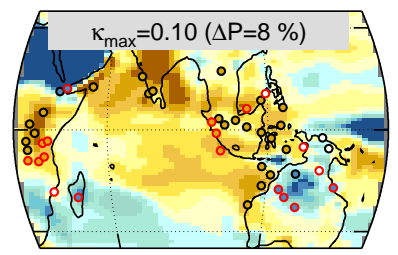

MRI-CGCM3
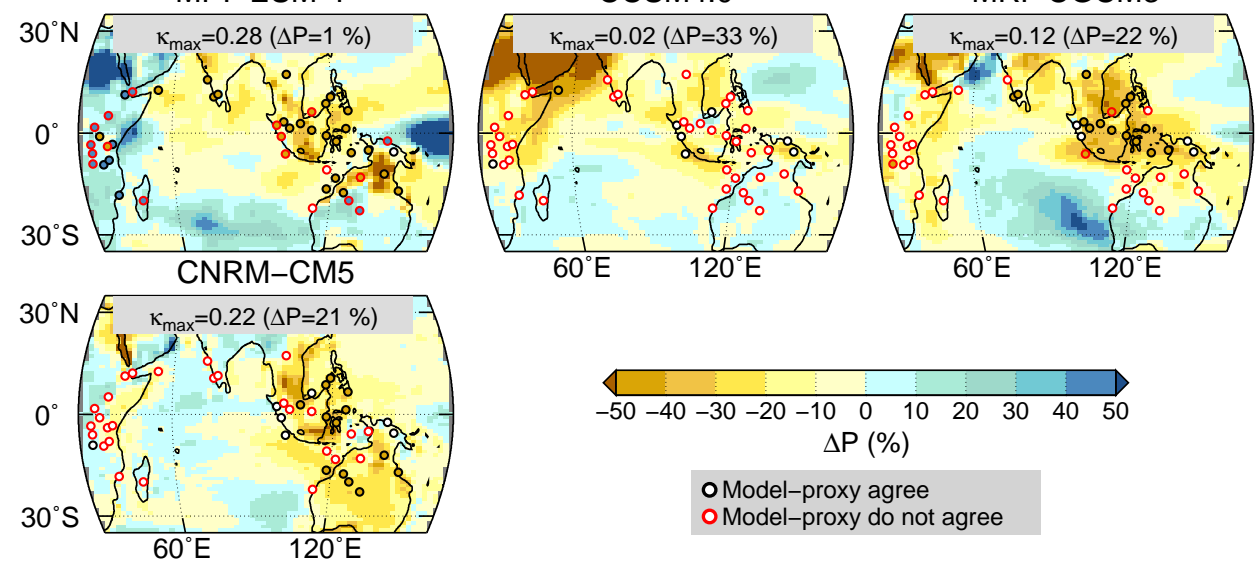

o Model-proxy agree

o Model-proxy do not agree 
(a)

(c) Proxy-model agreement
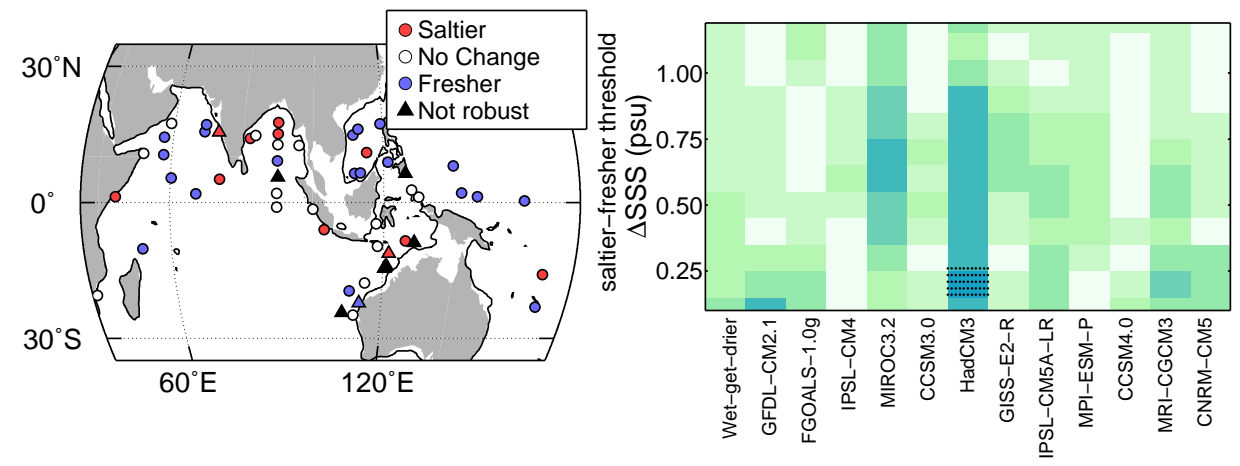

(b) Simulated sea-surface salinity change
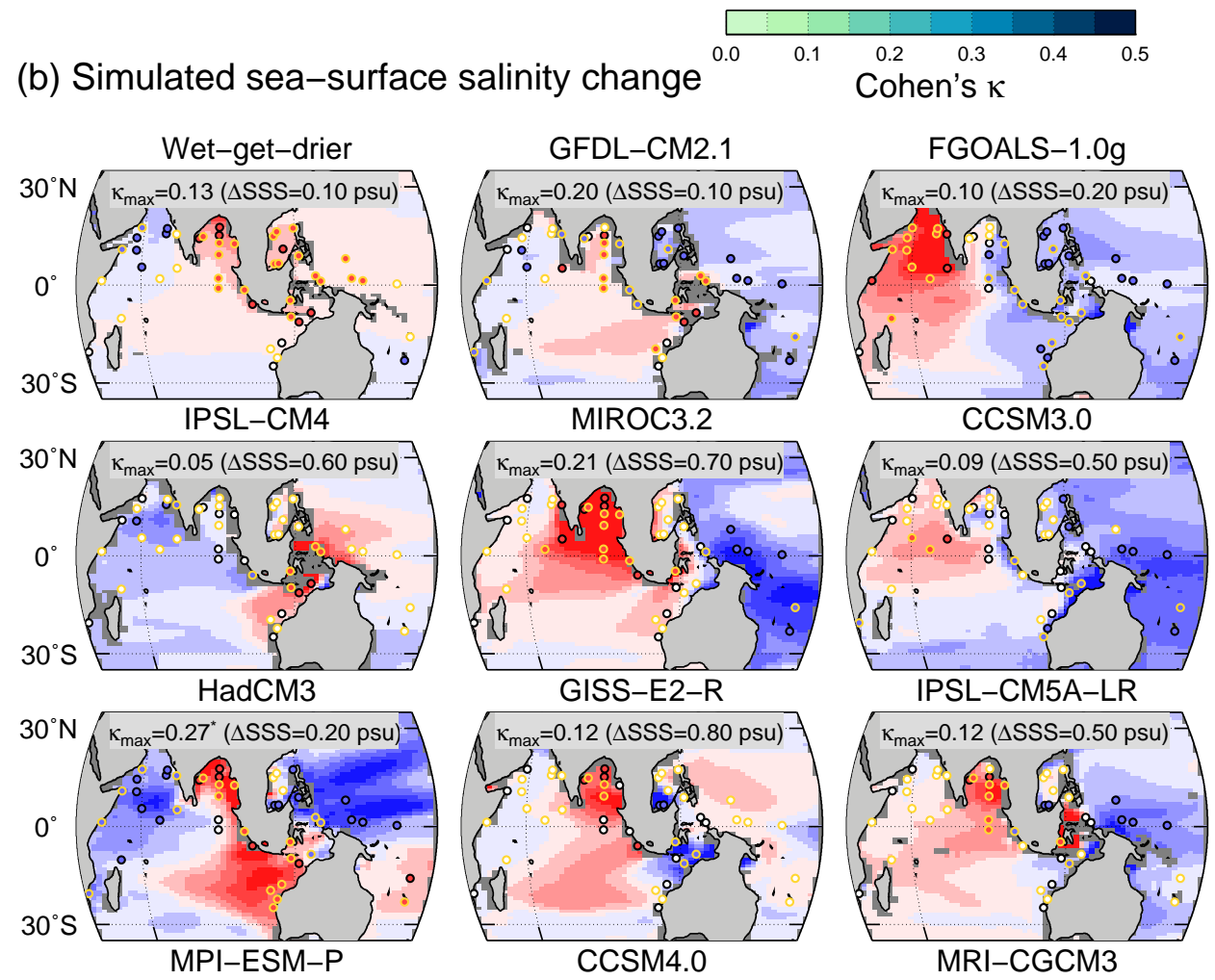

IPSL-CM5A-LR
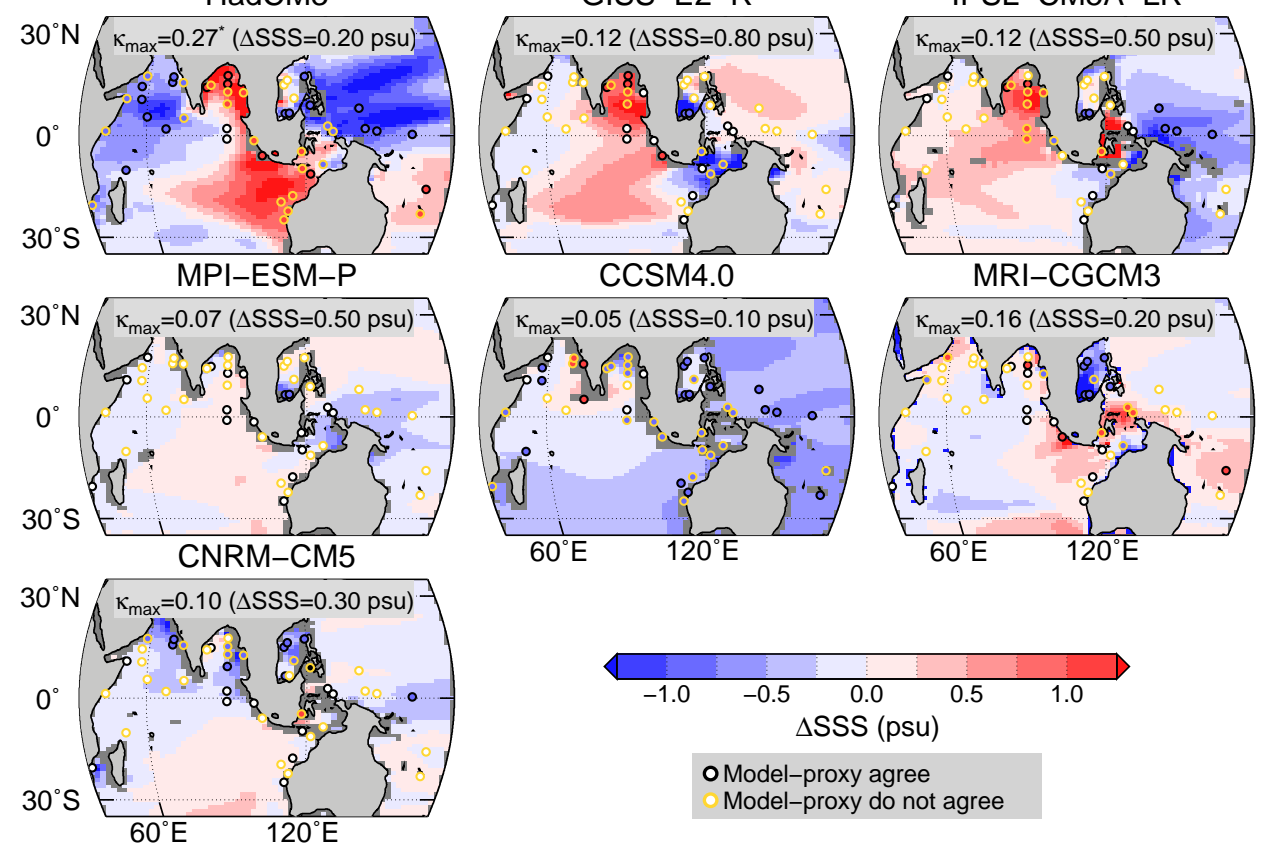

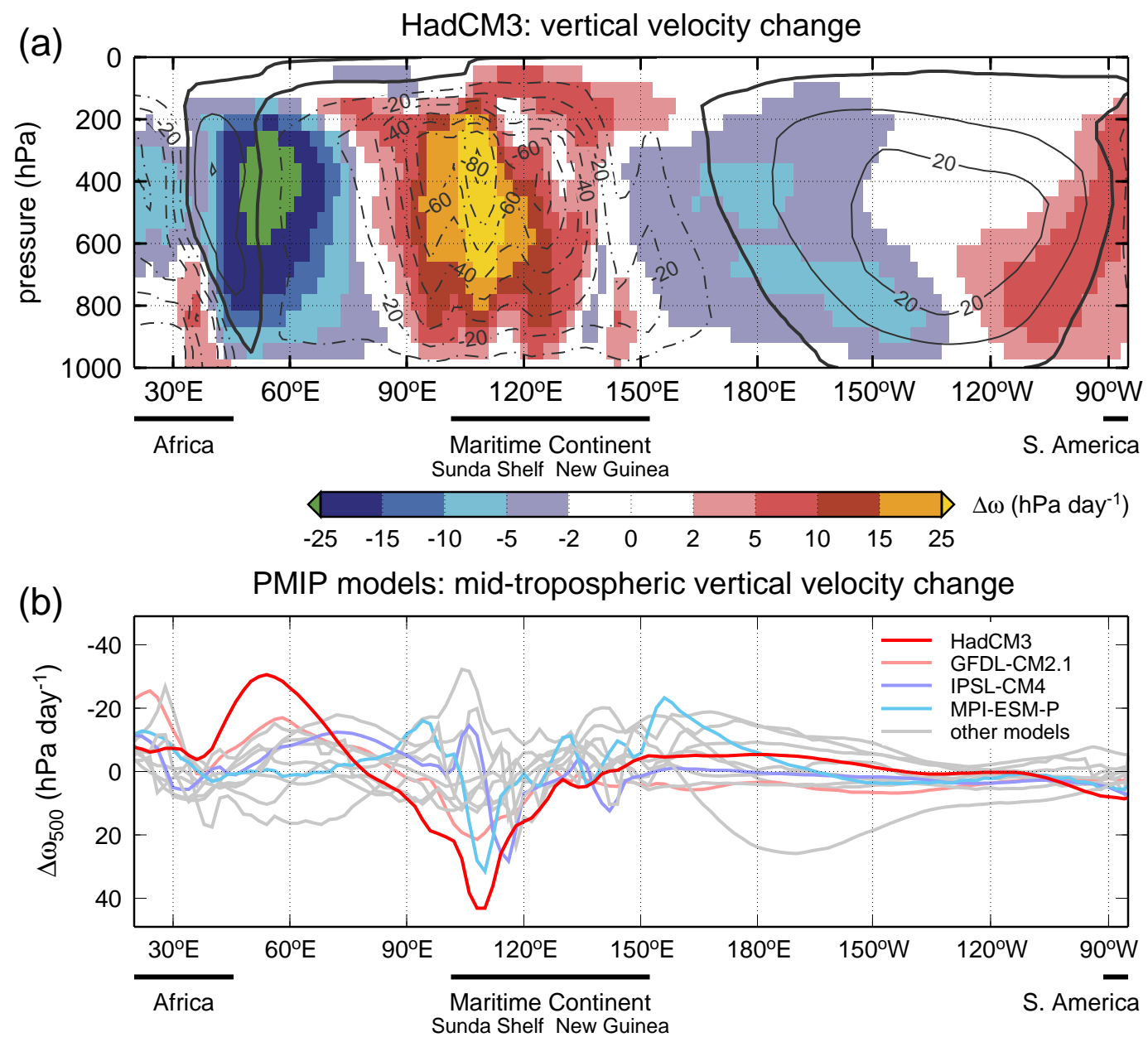
Figure 1 Present-day hydroclimate of the Indo-Pacific Warm Pool (IPWP). Observed annual-mean (a) rainfall ${ }^{36}$ and (b) sea-surface salinity ${ }^{37}$. Solid black contour indicates the IPWP boundaries as defined by the annual mean $28^{\circ} \mathrm{C} \mathrm{SST}{ }^{38}$ isoline. Dots indicate the locations of the (a) terrestrial and (b) marine proxies.

Figure 2 Proxy-model synthesis of LGM rainfall changes (a) Network of terrestrial proxies capturing drier (brown), unchanged (white), or wetter (blue) conditions at the LGM. Colored (black) triangles indicate locations where two or more proxies agree (disagree). Locations in the ocean denote marine cores in which terrestrial proxies were measured. Coastlines correspond to a $120 \mathrm{~m}$ drop in sea level. (b) Rainfall changes between LGM and pre-industrial $(\mathrm{PI})$ climate simulations expressed as a percentage of $\mathrm{PI}$ annual-mean precipitation. The maximum Cohen's $\kappa$ and optimal threshold for defining drier/wetter conditions is shown for each model. Asterisks indicate statistically significant $\kappa(p<0.05)$. (c) Cohen's $\kappa$ for each model as function of wetter/drier threshold. Stippling indicates statistically significant $(p<0.05) \kappa$ values.

\section{Figure 3 Proxy-model synthesis of LGM sea-surface salinity changes (a) Network} of marine proxies capturing saltier (red), unchanged (white), or fresher (blue) conditions at the LGM. Colored (black) triangles indicate locations where two or more proxies agree (disagree). Coastlines correspond to a $120 \mathrm{~m}$ drop in sea level. (b) Sea-surface salinity (SSS) changes between LGM and pre-industrial (PI) climate simulations. The maximum Cohen's $\kappa$ and optimal threshold for defining saltier/fresher conditions is shown for each 
model. Asterisks indicate statistically significant $\kappa(p<0.05)$. (c) Cohen's $\kappa$ for each model as function of saltier/fresher threshold. Stippling indicates statistically significant $(p<0.05) \kappa$ values.

\section{Figure 4 Simulated LGM changes in the Indo-Pacific Walker circulation. (a) Changes} in vertical velocity $(\omega)$ over the equatorial Indo-Pacific simulated by $\mathrm{HadCM} 3$ in response to LGM forcing (colors). Contours are annual-mean $\omega$ simulated in the pre-industrial control experiment. Contour intervals $=10 \mathrm{hPa} \mathrm{day}^{-1}$. Note that the colorscale is not linear. (b) Changes in vertical velocity at the $500 \mathrm{hPa}$ level $\left(\omega_{500}\right)$ over the equatorial IndoPacific simulated by twelve climate models in response to LGM forcing. Both panels show changes in $\omega$ averaged over the $10^{\circ} \mathrm{S}-5^{\circ} \mathrm{N}$ latitude band. 